\title{
Direct Electrodeposition of Highly Dense Bi/Sb Superlattice Nanowire Arrays
}

\author{
F.H.Xue, G.T.Fei*, B.Wu, P.Cui, L.D.Zhang \\ Key Laboratory of Materials Physics, Institute of Solid State Physics, Hefei Institutes of \\ Physical Science, Chinese Academy of Sciences.
}

\section{Supporting Information}

\section{Preparation and characterization of anodic alumina membrane (AAM)}

\section{Fabrication of $\mathrm{Bi} / \mathrm{Sb}$ superlattice nanowire arrays}

\section{Samples preparation for TEM and FE-SEM observation}

\section{Additional EDX results}

5. Additional supporting figures and the growth rate of $\mathrm{Bi}$ and $\mathrm{Sb}$ segments

\section{Preparation and characterization of anodic alumina membrane (AAM)}

Anodic alumina membrane (AAM) was prepared by electrochemical anodization method proposed by Masuda et at. Prior to anodizing, high-purity aluminum foil $(99.999 \%)$ was annealed at $500^{\circ} \mathrm{C}$ for $5 \mathrm{~h}$ in a vacuum of $10^{-3} \mathrm{~Pa}$ to release the mechanical stress and obtain homogenous structure over a large area. Then the aluminum foil was electropolished at $23 \mathrm{~V}$ in a mixture solution of $70 \%$ perchloric acid and ethanol $(1: 9)$ at $4^{\circ} \mathrm{C}$ for $5 \mathrm{~min}$. The AAM was prepared using a two-step anodization process. First, anodization was carried out at 40V DC in 0.3M aqueous oxalic acid electrolyte at $15^{\circ} \mathrm{C}$ for $5 \mathrm{~h}$ (Figure S-1(a)), then the membrane was emerged into the mixture solution consisting of $1.5 \mathrm{wt} \%$ chromic acid and $6 \mathrm{wt} \%$ phosphoric acid at $60^{\circ} \mathrm{C}$ for $6 \mathrm{~h}$ to remove the alumina layer formed at the above step (Figure $\mathrm{S}-1(\mathrm{~b})$ ). Subsequently the aluminum foils were oxidized again for $12 \mathrm{~h}$ at the same conditions as that mentioned above (Figure S-1(c)). After the second anodization, the remaining aluminum substrate was removed in a saturated $\mathrm{SnCl}_{4}$ solution (Figure $\mathrm{S}-1$ (d)). Finally, 
the thought-hole AAM template was obtained after dissolving the alumina barrier layer in $6 \mathrm{wt} \%$ phosphoric acid solution at $30^{\circ} \mathrm{C}$ for $60 \mathrm{~min}$ (Figure S-1(e)). Moreover, the pore diameter can be further enlarged by immersing $\mathrm{AAM}$ into in a $5 \mathrm{wt} \% \mathrm{H}_{3} \mathrm{PO}_{4}$ solutions (Figure S-1(f)), and the pore size can be adjusted by controlling the etching time. Field emission microscopy observations indicate that the AAM has an almost perfect hexagonally arranged nanopore arrays, as shown in Figure S-2.

(a)

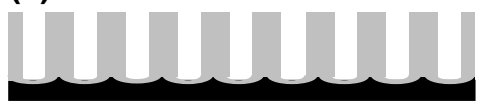

(b)

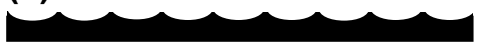

(c)

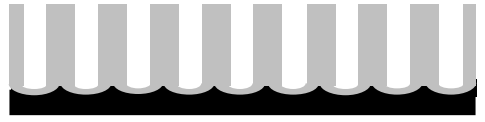

(d) (e)

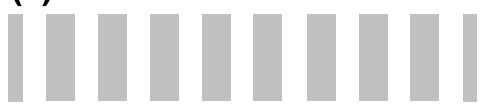

(f)

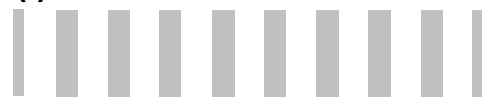

(g)

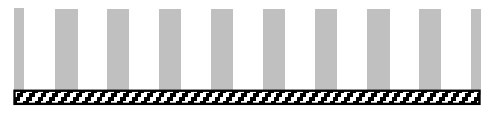

\section{Aluminum $\mathscr{W}$ Au layer \\ Alumina}

Figure S-1. The preparation process of the AAM template; (a) membrane after the first anodization; (b) removing the alumina layer made on the first step; (c) aluminum foils oxidized again; (d) after etching remaining aluminum substrate; (e) dissolving the alumina barrier layer on the bottom of the foil; ( $f$ ) enlarging the pores of AAM; $(g)$ sputtering an Au film onto one surface of $A A M$.
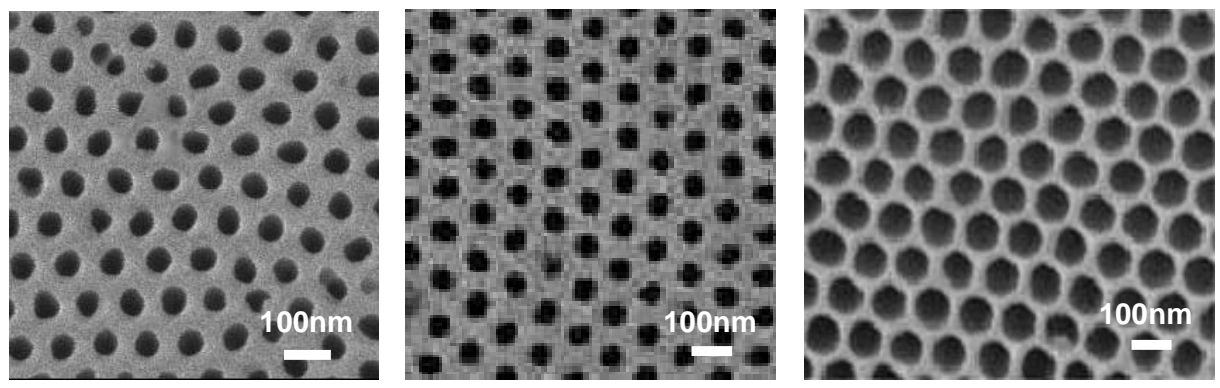

Figure S-2. FE-SEM images of AAM template after a pore-widening process in 5 wt\% phosphoric acid at $30^{\circ} \mathrm{C}$ for (a) $3 \mathrm{~min}$, (b) $5 \mathrm{~min}$ and (c) $8 \mathrm{~min}$.

\section{Fabrication of $\mathrm{Bi} / \mathrm{Sb}$ superlattice nanowire arrays}

\section{(a) Experiment setup}


For the electrochemical deposition of $\mathrm{Bi} / \mathrm{Sb}$ superlattice nanowires, an Au film with thickness of about $200 \mathrm{~nm}$ was sputtered onto one side of the AAM template to serve as the working electrode (Figure $\mathrm{S}-1(\mathrm{~g})$ ).

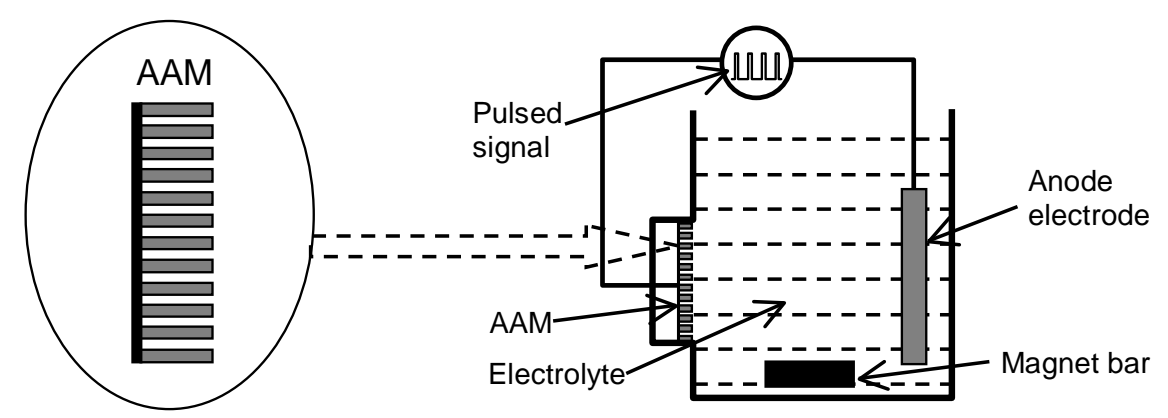

Figure S-3. Experiment setup for synthesis $\mathrm{Bi} / \mathrm{Sb}$ superlattice nanowire arrays

The experiment setup for the electrochemical deposition of $\mathrm{Bi} / \mathrm{Sb}$ superlattice nanowires is shown in Figure S-3. The AAM coated with an Au film on one side was used as the cathode electrode, while a graphite plate was used as the anode electrode. The electrolyte consisted of $0.01 \mathrm{M} \mathrm{BiCl}_{3}, 0.08 \mathrm{M} \mathrm{SbCl}_{3}, 0.2 \mathrm{M} \mathrm{H}_{3} \mathrm{BO}_{3}, 0.01 \mathrm{M}$ $\mathrm{C}_{4} \mathrm{H}_{6} \mathrm{O}_{6}$ and $0.1 \mathrm{~g} \mathrm{CH}_{3}\left(\mathrm{CH}_{2}\right) 11 \mathrm{SO}_{3} \mathrm{Na}$, and the initial $\mathrm{pH}$ value was adjusted to 2 by adding appropriate amounts of $\mathrm{HCl}$. A pulsed signal generated by a home-made equipment add on the two electrodes to prepare the modulated $\mathrm{Bi} / \mathrm{Sb}$ superlattice nanowire arrays. In the preparation process, a magnetic bar is keeping stirring to ensure the homogeneity of the electrolyte.

\section{(b) The parameter selection of $\mathrm{Bi} / \mathrm{Sb}$ superlattice nanowires preparation}

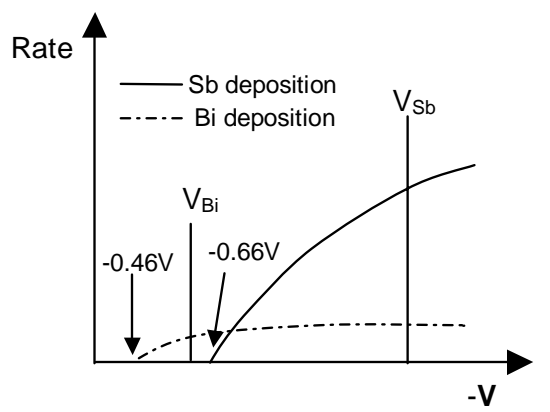

Figure S-4. The sketch map of $\mathrm{Bi}$ and $\mathrm{Sb}$ electrodepositing rate under different potentials.

The current and voltage curves of $\mathrm{Bi}$ and $\mathrm{Sb}$ segments deposition are show in Figure. S-4. The standard electrode potential of $\mathrm{Bi}$ and $\mathrm{Sb}$ are $-0.46 \mathrm{~V}$ and $-0.66 \mathrm{~V}$ respectively, which means that $\mathrm{Bi}$ can only be deposited under the potential of $-0.46 \mathrm{~V}$, 
and $\mathrm{Sb}$ can only be deposited under $-0.66 \mathrm{~V}$. When the potential of above $-0.46 \mathrm{~V}$ is applied, the deposition could not occur. Furthermore, only Bi can be embedded into the pores under a potential between $-0.46 \mathrm{~V}$ and $-0.66 \mathrm{~V}$. However, when the potential is lower than $-0.66 \mathrm{~V}$, both $\mathrm{Bi}$ and $\mathrm{Sb}$ components can be deposited together.

Considering the influence of the potential on the components deposited, we took a potential of $-0.6 \mathrm{~V}$ to deposit almost pure $\mathrm{Bi}$ segments and a potential of $-1.4 \mathrm{~V}$ to fabricate the segments of majority of $\mathrm{Sb}$ in company with a little trace of $\mathrm{Bi}$. In the $\mathrm{Bi}$ segments deposition, almost pure Bi segments were obtained since only Bi element can be deposit in the potential of $-0.6 \mathrm{~V}$. However in Sb segments deposition, element $\mathrm{Bi}$ can be co-deposited with $\mathrm{Sb}$ under the potential of $-1.4 \mathrm{~V}$. In our experiment, the concentration of $\mathrm{Bi}^{3+}$ is low in the electrolyte, and the concentration of $\mathrm{Sb}^{3+}$ is much high than that of $\mathrm{Bi}$. In this case, Bi growth rate (as the dash dot curve shown in Figure $\mathrm{S}-4$ ) increased much slowly than that of $\mathrm{Sb}$ (as the solid curve shown in Figure S-4) with decreasing potential. It is seemed that more negative potential would result in a high quality $\mathrm{Sb}$ segments. Nevertheless, the pores filling ratio decreased and the interfaces of the product became rough as the potential decreased, therefore, the potential could not decrease infinity. We have tried many potentials and found that a potential of $-1.4 \mathrm{~V}$ might be a good choice. In addition, we could obtain much longer $\mathrm{Bi}$ or $\mathrm{Sb}$ segments by increasing the deposition time, and some $\mathrm{Bi} / \mathrm{Sb}$ superlattice nanowire arrays have been prepared in the paper.

\section{Samples preparation for TEM and FE-SEM observation}

The morphology of $\mathrm{Bi} / \mathrm{Sb}$ superlattice nanowire arrays was observed by field emission scanning electron microscopy (FE-SEM, FEI Sirion 200) and transmission electron microscopy (TEM, JEOL-2010). Energy dispersive x-ray microanalysis (EDX) attached to FE-SEM was used to analyze the elements composition. The specimen for SEM observation was obtained by dissolving upper part of the AAM in a solution of $5 \mathrm{wt} \%$ sodium hydroxide at room temperature for 15 minutes, in this cases, there is only a part of AAM was removed. Subsequently, a thin Au film was sputtered onto specimen to avoid charging with the FE-SEM observation. For TEM observation, the specimens were put into $5 \mathrm{wt} \%$ sodium hydroxide solution to dissolve the AAM completely, then rinsed with deioned-water for several times and afterwards dispersing the superlattice nanowires in ethanol by ultrasonic vibration. Finally, put several drops of ethanol dispersed with the superlattice nanowires on a copper grid covered with carbon films for TEM observation. 


\section{Additional EDX results}

It is very difficult to check the concentration on the so short $\mathrm{Bi}, \mathrm{Sb}$ segments in $\mathrm{Bi} / \mathrm{Sb}$ superlattice nanowires by an energy dispersive $\mathrm{x}$-ray microanalysis (EDX), so we fabricated two kinds of samples in the same condition described previously. Sample (a) and sample (b) were prepared under the potential of $-0.6 \mathrm{~V}$ and $-1.4 \mathrm{~V}$, which we used to deposit $\mathrm{Bi}$ segments and $\mathrm{Sb}$ segments in the preparation of $\mathrm{Bi} / \mathrm{Sb}$ superlattice nanowires, respectively, in the same electrolyte mentioned above. In this case, the components of the sample (a) and sample (b) should be similar to that of $\mathrm{Bi}$ and $\mathrm{Sb}$ segment in the $\mathrm{Bi} / \mathrm{Sb}$ superlattice nanowires, respectively. EDX spectrums were shown in Figure S-5, and it can be found besides $O$ and Al, which come from AAM templates, only elements $\mathrm{Bi}$ and $\mathrm{Sb}$ can be found. The relative concentration of $\mathrm{Bi}$ and $\mathrm{Sb}$ are list in Table S-1. The result indicate that the component of the nanowires prepared under the potential of $-0.6 \mathrm{~V}$ consists of $95.7 \% \mathrm{Bi}$ and $4.3 \% \mathrm{Sb}$, and the component of the nanowires prepared under the potential of $-1.4 \mathrm{~V}$ consists of $86.7 \% \mathrm{Sb}$ and $13.3 \% \mathrm{Bi}$. These EDX results indicate that there are no more than $5 \% \mathrm{Sb}$ existing in $\mathrm{Bi}$ segment, and no more than $15 \% \mathrm{Bi}$ existing in $\mathrm{Sb}$ segment in the $\mathrm{Bi} / \mathrm{Sb}$ superlattice nanowires.

In order to comparing the effect of the deposition potential on the concentration ratio, we also prepared the nanowires under a potential of $-1.2 \mathrm{~V}$. The EDX curve is shown in Figure S-5(c), and the relative concentrations are also list in Table S-1. The EDX analysis shows that the nanowires consist of $21.9 \% \mathrm{Bi}$ and $78.1 \% \mathrm{Sb}$. Compared with the sample (b), it can be found that, in nanowires preparation, we can fabricate segments with more $\mathrm{Sb}$ content by depositing under a much negative potential. Nevertheless, the potential can not decrease infinity to get a better quality of $\mathrm{Sb}$ segment, because the electrodeposition is a much complex process, many factor such as the roughness of the interface, pore filling ratio etc should be considerate. Many experiment suggest that a potential of $-1.4 \mathrm{~V}$ may be a good choice. 

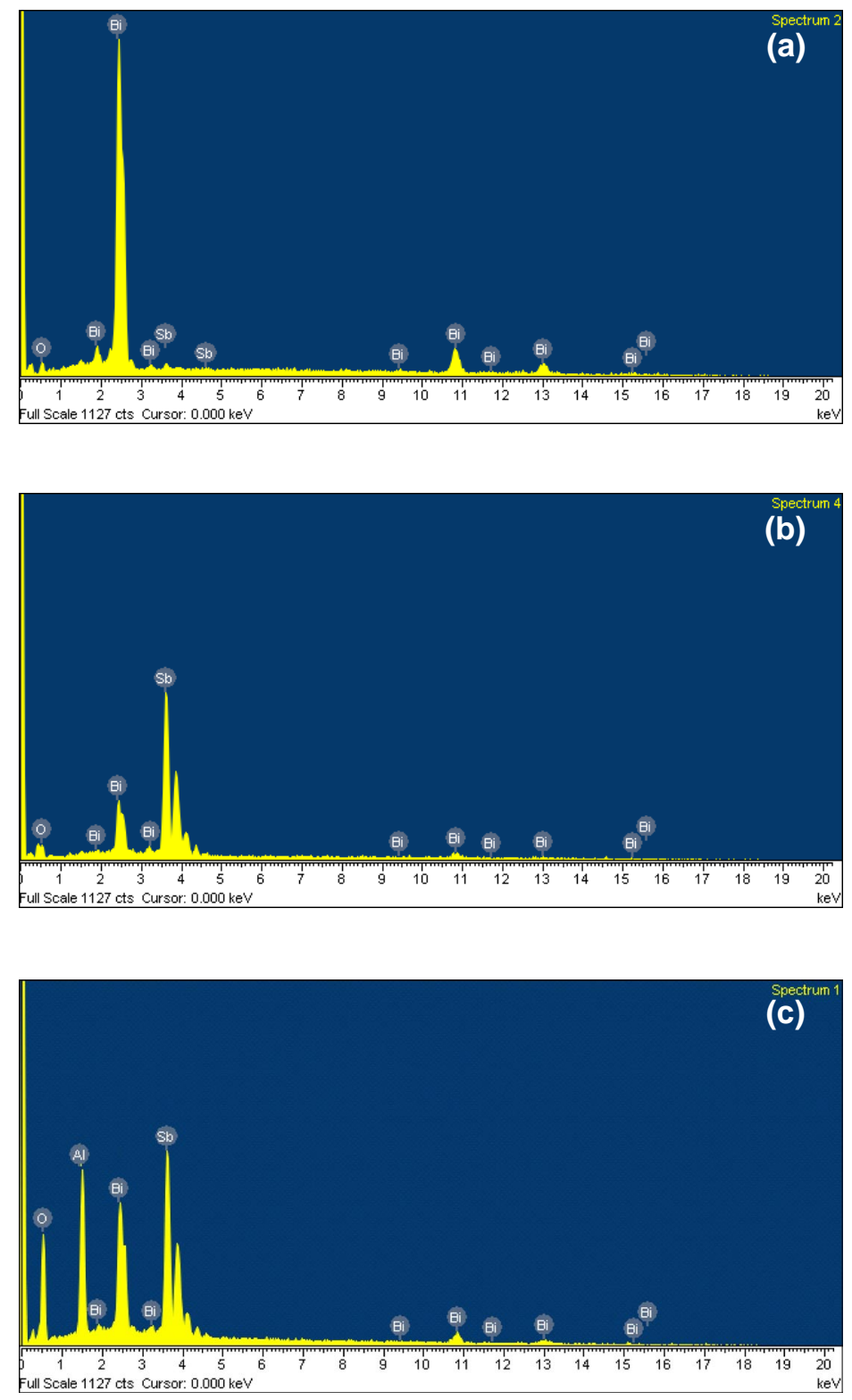

Figure S-5. EDX spectra of the nanowire arrays fabricated under the potentials of (a)-0.6V, (b) $-1.4 \mathrm{~V}$, and (c)-1.2V.

Table S-1. Concentration of samples prepared at different potential

\begin{tabular}{|c|c|c|c|}
\hline & Deposite potential & Bi content & Sb content \\
\hline Sample (a) & $-0.6 \mathrm{~V}$ & $95.7 \%$ & $4.3 \%$ \\
\hline Sample (b) & $-1.4 \mathrm{~V}$ & $13.3 \%$ & $86.7 \%$ \\
\hline Sample (c) & $-1.2 \mathrm{~V}$ & $21.9 \%$ & $78.1 \%$ \\
\hline
\end{tabular}




\section{Additional supporting figures and the growth rate of $\mathrm{Bi}$ and $\mathrm{Sb}$ segments}

By changing depositing time for $\mathrm{Bi}$ and $\mathrm{Sb}$ segments and keep other conditions constant, as mentioned above, some typical $\mathrm{Bi} / \mathrm{Sb}$ superlattice nanowires have been successfully synthesized as shown in Figure.S-6. The depositing time for both $\mathrm{Bi}$ and $\mathrm{Sb}$ segments are list in Table S-2. The diameters of these nanowires are about $50 \pm 5$ $\mathrm{nm}$. The relationship of depositing time and length of $\mathrm{Bi}$ and $\mathrm{Sb}$ segments are shown in Figure.S-7, which indicates that depositing time and segment length are almost linear. The growing rates of $\mathrm{Bi}$ and $\mathrm{Sb}$ segments are about $1.5 \mathrm{~nm}$ and $6.7 \mathrm{~nm}$ per second with a little fluctuation.
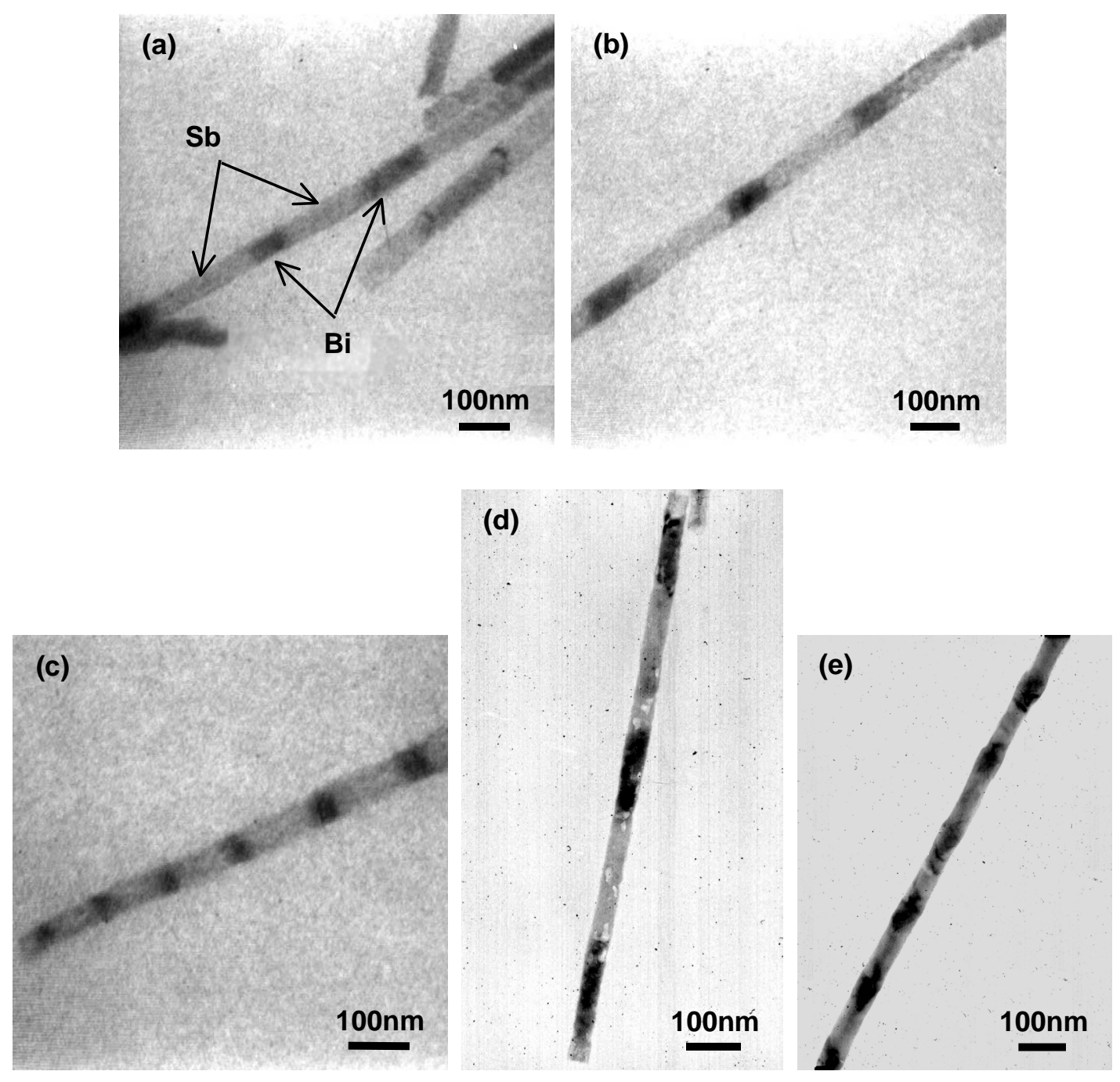


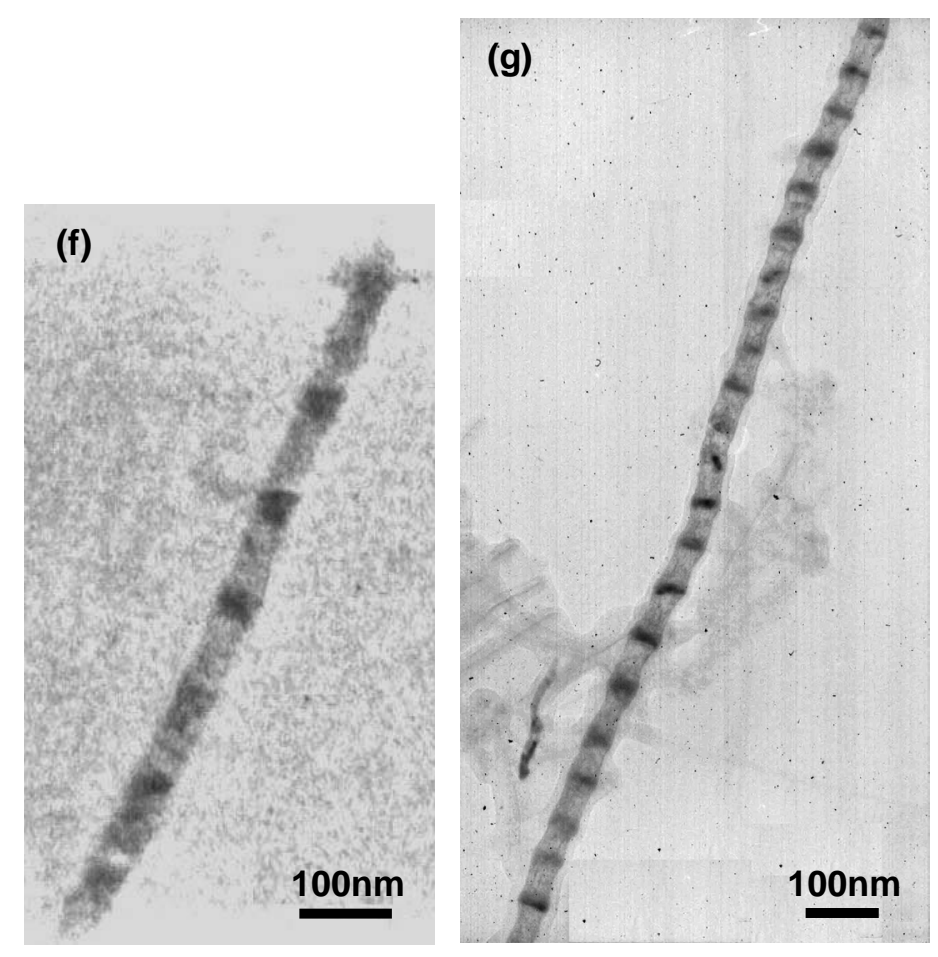

Figure S-6. Additional figures of superlattice nanowires.

Table S-2. parameters of the samples and correspond depositing time.

\begin{tabular}{|c|c|c|c|c|}
\hline & Bi seg. $(\mathrm{nm})$ & Sb seg. $(\mathrm{nm})$ & $\mathrm{t}_{\mathrm{Bi}}(\mathrm{s})$ & $\mathrm{t}_{\mathrm{Sb}}(\mathrm{s})$ \\
\hline Sample a & 45 & 90 & 30 & 15 \\
\hline Sample b & 80 & 160 & 50 & 25 \\
\hline Sample c & 90 & 230 & 60 & 35 \\
\hline Sample d & 200 & 350 & 130 & 50 \\
\hline Sample e & 90 & 100 & 60 & 15 \\
\hline Sample f & 50 & 100 & 35 & 15 \\
\hline Sample g & 18 & 65 & 12 & 10 \\
\hline
\end{tabular}
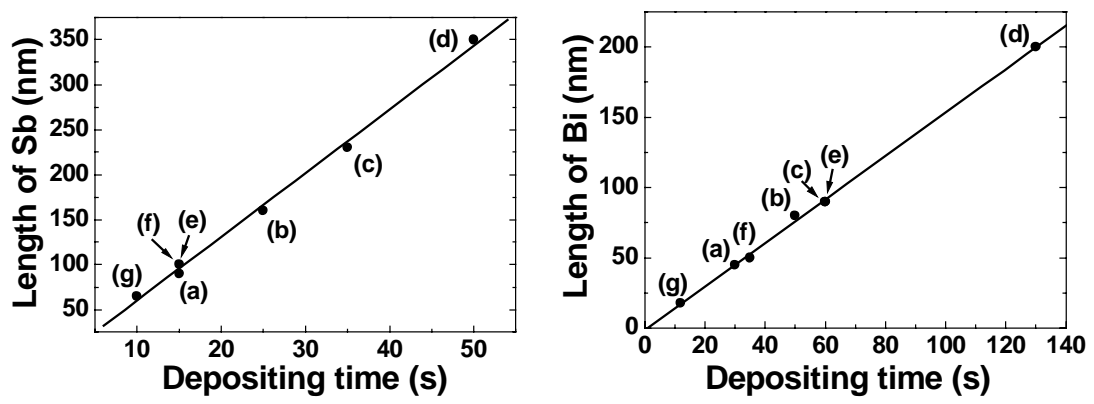

Figure S-7. Length vs. depositing time for the segments Bi (a) and $\mathrm{Sb}$ (b). 
In order to compare the influence of potential on the interface between Bi segment and $\mathrm{Sb}$ segment, $\mathrm{Bi} / \mathrm{Sb}$ nanowires were fabricated with $\mathrm{Sb}$ segments made under potential -1.2V. EDX spectrum (Table S-1(c)) indicates that Bi content in Sb segment is about 22\%. Comparing Fig.S-6. and Fig.S-8., it can be found that the interface is not clear when $\mathrm{Sb}$ segments deposition with the potential of $-1.2 \mathrm{~V}$, which indicate that the interface would become abrupt as the Sb segments depositing potential decreased.
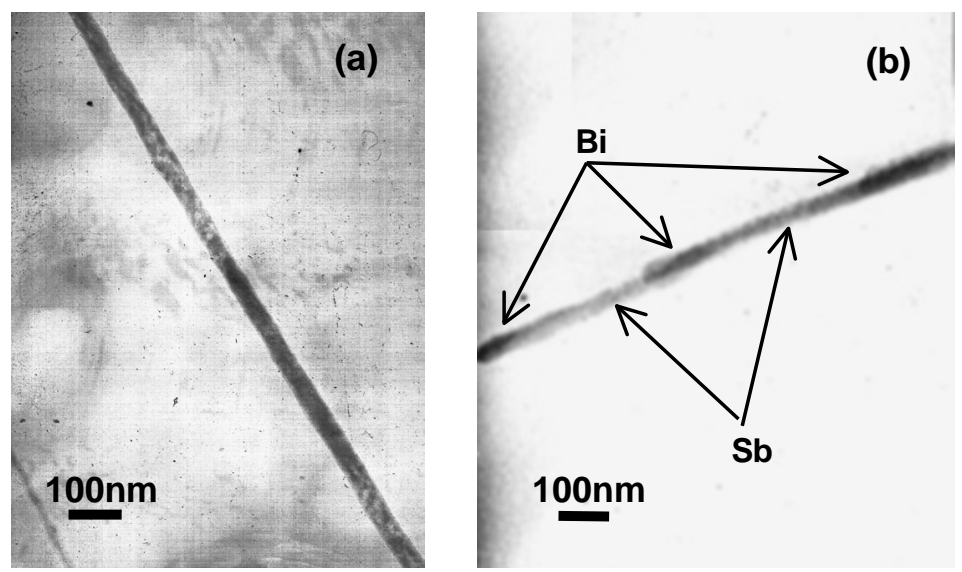

Figure S-8. Nanowires were prepared with Sb segments deposited under potential $-1.2 \mathrm{~V}$ 